\title{
PADRÕES DE CRESCIMENTO DO SETOR DE CULTURAS DO ESTADO DO ESPIRITO SANTO
}

\author{
ROBERTO AMADEU FASSARELLA \\ Engenhelro Agrônomo
}

Orientador: Prơo Dr. SÉRGIO ALBERTO BRANDT

Dissertação apresentada à Escola Superior de Agricultura "Luiz de Queiroz", da Universidade de São Paulo, para obtenção do título de Mestre em Agronomia, Área de

Concentração: Economia Agrária.

PIRACICABA

Estado de São Paulo - Brasil

Maio - 1987 
À Märcia, ao Yuri e à Luiza, pelas horas que esta Tese thes roubaram.

A Honório in memorian e Henriqueta,

pelo exempio de honestidade, trabalho e dedicasão. 


\section{AGRADECIMENTOS}

Ao Departamento de Economia e Sociologia Rural da ESALQUSP, pelas excelentes condições de estudo e trabalho oferecidas.

Ao Departamento de Zootecnia e Economia Rural da UFES, pela oportunidade que nos foi concedida.

Ao Professor Sérgio Alberto Brandt pela orientação e colaboração prestadas.

Ao Professor Geraldo Sant'Ana de Camargo Barros pelas críticas e sugestões oferecidas.

Ao Professor Fernando Curi Peres, pelos comentários e colaborações prestados.

Ao Professor Cicely iloitinho Amaral, pela orientação inicial.

Aos Colegas João Pizysirznig Filho e Luiz Carlos Estraviz Rodrigues pela colaboração no processamento dos dados.

A todos aqueles que, direta ou indiretamente, contribuí ram para o bom andamento desta pesquisa. 


\section{SUMARIO}

Página

LISTA DE TABELAS $\ldots \ldots \ldots \ldots \ldots \ldots \ldots \ldots \ldots \ldots \ldots \ldots$

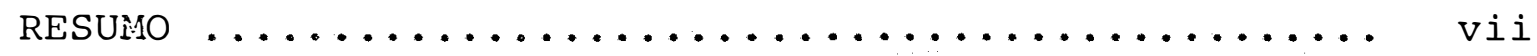

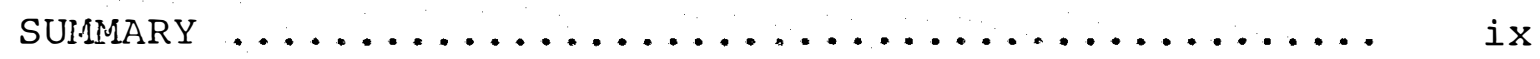

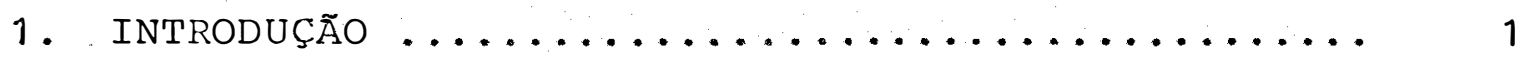

2. REVISÄO DE LITERATURA ..................... 4

3. MATERIAL E METODOS ..................... 8

4. ANÁLISE DOS RESULTADOS ........................... 16

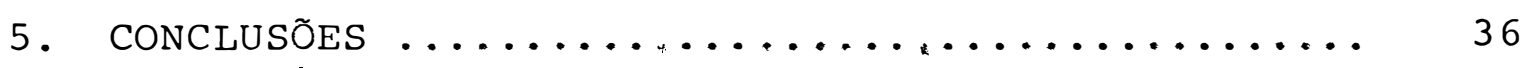

6. REFERENCIAS BIBLIOGRÁFICAS .................. 39 


\section{IISTA DE TABELAS}

Página

Tabela 1: Resultados da Análise de Shift-Share dos Efeitos de Área, Rendimento e Composição Sobre a Taxa de Crescimento do Produto Agrícola, Estado do Espirito Santo, 1970-

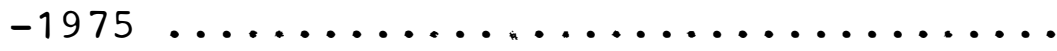

Tabela 2: Resultados da Análise de Shift-Share dos Efeitos de Área, Rendimento e Composição Sobre a Taxa de Crescimento do Produto Agrícola, Estado do Espirito Santo, 1975-

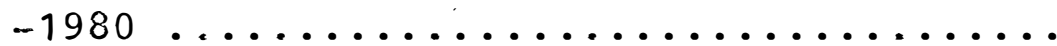

Tabela 3: Resultados da Análise de Shift-Share dos Efeitos de Ārea, Rendimento e Composição Localizada Sobre a Taxa de Crescimento do Produto Agrícola, Estado do Espíriro San-

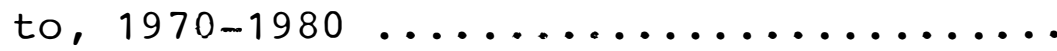

Tabela 4: Análise de Shift-Share das Taxas Geomé tricas de Crescimento dos Produtos de Lavouras. Decomposição dos Efeitos de Área $(E A)$, Rendimento (ER) e de Localização Geográfica (EL), Estado do Espírito Santo,

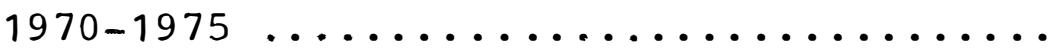


Tabela 5: Análise de Shift-Share das Taxas Geomé tricas de Crescimento dos Produtos de Lavouras. Decomposição dos Efeitos de Area $(E A)$, Rendimento (ER) e de Localização Geográfica (EL), Estado do Espírito Santo,

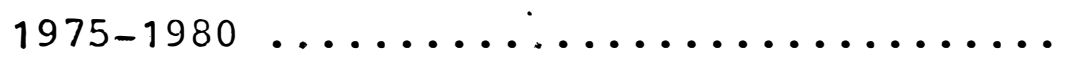

Tabela 6: Análise de Shift-Share das Taxas Geomé tricas de Crescimento dos Proảutos de Lavouras. Decomposição dos Efeitos de Área $(E A)$, Rendimento (ER) e de Localização Geográfica (EL), Estado do Espírito Santo,

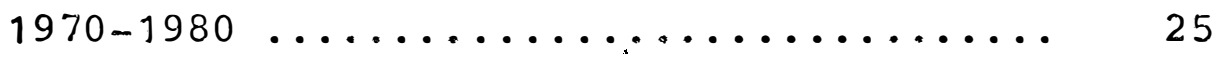




\title{
PADRÕES DE CRESCIMENTO DO SETOR DE CULTURAS DO ESTADO DO ESPIRITO SANTO
}

\author{
Autor: ROBERTO AMADEU FASSARELLA \\ Orientador: Prof? Dr. SËRGIO ALBERTO BRANDT
}

\section{RESURO}

O objetivo desta pesquisa é o de quantificar as fontes e diferenças regionais de crescimento do subsetor de cultivos da agricultura do Espirito Santo na década de 1970 e também identificar determinantes dessas mudanças.

Para isso faz-se uso da versão modificada do modelo shift-share. Esse método permite, comparando-se períodos, uma análise individual das culturas e também da influência de composição e distribuição regional sobre o desem penho global das lavouras.

Na década de 1970, o setor agrícola do Estado do Espirito Santo cresceu a uma taxa de 3,5\% a.a. O efejto-rendimento e o efeito-composição contribuiram de maneira positiva para esse crescimento. Pode ter contribuido para esse efeito-rendimento positivo as politicas de incentico à modernização, como a expansão dos serviços de extensão rural e de crédito subsidiado, que possibilitaram o uso de insumos modernos, como fertilizantes, defensivos e senentes melhoradas. A importância do efeito-composição se deve a reimplantação das lavouras cafeeiras no Estado, com novos padrões tecnológicos, através do plano de revigoramento dos cafezais capixabas. Isso fez com que os municípios onde essa lavoura mais se expandiu acusassem as maiores taxas dẹ crescimento 
do oroduto agrícola, sendo o efeito-composição um dos princi pais responsáveis por esse crescimento.

O efeito-área teve uma participação negativa na explicação do crescimento da agricultura do Espirito Santo na década de 1970, ficando em torno de $-1,4 \%$ a.a. A retração das culturas se deve a expansão das áreas com pasta gens e reflorestamento, ambos incentivados por politicas governamentais.

Com relação a análise das culturas indivicualmente, na década de 1970 no Espírito Santo, os resultados da análise indicam que as culturas de consurno interno como arroz, mandioca, milho e banana acusaram taxas negativas de crescimento.

A produção de arroz e o milho decresceram de vido a retração nas áreas, já que o efeito-área é negativo. o decréscimo na produção não foi maior graças ao efeito-rendimento positivo. Contribuiu para a queda na produção da mandioca o efeito-área negativo. Na taxa de crescimento negativo da produção de banana contribuiu de forma significa tiva e efeito-rendimento de $-7,34 \%$. A produção do feijão estagnou no Espírito Santo naquela década, permanecendo cons tante o rendimento e a área plantada. O tomate apresentou uma elevada taxa de crescimento, tendo contribuído para esse incremento em ordem de importância o efeito-rendimento, seguido do efeito-localização. A cana-de-açúcar cresceu na década de 1970 a uma taxa de $2 \%$, tendo contribuído para isso o efeito-rendinento e localização.

As culturas de exportação como café e o cacau apresentaram taxas relativamente elevadas de crescimento na produção. Para o cacau contribuiu para esse incremento na produção um efeito-rendimento elevado ao passo que o café, além do efeito-rendimento, o efeito-localização geográfica da produção. 


\section{GROWTH PATTERNS OF THE STATE OF ESPIRITO SANTO CROP SECTOR}

Author: ROBERTO AMADEU FASSARELLA

Adviser: Profo Dr. SERGIO ALBERTO BRANDT

\section{SUMMARY}

The objective of this research is to quantify the regional sources and differences in growth rates of the crop sector of the State of Espirito Santo, Brazil. The study covers the period of 1970 to 1980 and also intends to identify the causes of those changes.

In order to achieve those objectives a modified version of the shift-share model isused. This procedure permits, by means of inter-period comparisons, a specific analysis of individual crops. The effects of regional composition and distribution on crop global performance, are also analysea.

In the periods of 1970 , the agricultural

sector of the state of Espirito Santo grew at a rate of $3,5 \%$ a year. The yieldeffect and the composition effect contributed in a positive way to this crop output growth. The modernization politicies, as well as the expansion of rural extension and subsidized credit, may be associated to this yield effect. The importance of composition effect is atributed to reimplantation of coffee farming in the state of Espirito Santo, with new tecnological standard, through coffee reinvigorating plans in the state of Espirito Santo.

The acreage effect had a negative participation on the agricultural growth explanation in the state of Espirito 
Santo in periods of 1970, remaining at an aproximate rate of $-1,48 \%$ a year. The retraction of crop areas is atributed to the expansion of grazing and reflorestation ground, both of them incentivated by government politicies.

Concerning with the individual farming analysis, in periods of 1970 in the state of Espirito Santo, the results of the analysis indicate that domestic consunption crops such as rice, cassava, corn and and banana determined negative rates of growth.

The rice and corn crops decreased due to the retraction in acreage. The decrease in the rice and corn crops wasn't bigger because of the positive yield effect. The negative acreage effect contributed to the cassava crop decrease. The negative yield effect of $-7,34 \%$ contributed in a significant way to the negative growth rate of banana crop. Beans crop in the state of Espirito santo in the period of 1970, remained at the same yield and same cultiveted area. Tomato crops presented a high growth rate because of the yield effect and secondarily the location effect. Sugar cane crops increased in the period of 1970 at a rate of $2 \%$ a year, having the yield effect and location effect contributed to this growth.

The exportation farmings such as coffee and cocoa presented relative high growth rate in crops. The yield effect and secondarily the geographical location effect contributed to the coffee growth crop. 


\section{INTRODUÇÃO}

A preocupação com as diferenças regionais de crescimento do setor agrícola tem sido uma constante entre pesquisadores, politicos e lideres em geral, por reconhece rem a importância da agricultura no desenvolvimento econômico.

Assim, é relevante a obtenção de indicadores de desemp̣enho da agropecuária pois, além de refletir mudan ças nas fontes de seu crescimento, auxiliam na formulação politicas agricolas.

No estado do Espírito Santo, poucos trabalhos tem sido realizados neste sentido. Estes poucos estudos se linitam a análises de mercado e de influēncias de melhorias na infra-estrutura econômica sobre o crescimento agrícola, ou analisam o conjunto da agropecuária. Pouco ou quase nada se tem feito para estuảar as fontes de crescimento do subsetor de culturas, conhecendo-se somente alguns resultados de pesquisas feitos a nível de País, e que expressam, de forma sumária, o comportamento do setor de culturas do Espírito Santo.

O presente trabalho tem por objetivo princinal. quantificar as fontes e diferenças regionais de crescimento do setor de culturas da agricultura capixaba, na década de 1970 e, também, identificar os determinantes dessas madanças.

Faz-se uso de versão modificada do modelo shift-share, também denominado modelo diferencial-estrutural. 
Esse método permite, comparando-se períodos, uma análise individual das culturas e também da influência de composição e distribuição regional sobre o desempenho global do subsetor. Torna-se então possível indicar às partici pações de variações de área, rendimento, composição e loca lização geográfica das culturas, na variação global do produto agrícola.

Baseando-se no critério de maior expressividade econômica, são analisadas as seguintes culturas: arroz, cana-de-açúcar, feijão, mandioca, milho, tomate, banana, cacau e café.

A escolha da década de 1970 se deve, principalmente, a dois motivos. O primeiro motivo é que, graças à evolução tmeporal do mercado internacional do café, esta lavoura começou a expandir-se no Estado, e com orientação do Instituto Brasileiro do Café - IBC, foi implantada em áreas mais propícias e com novos padrões tecnológicos, que garan tiram maior produtividade ${ }^{1}$. Por outro lado, culturas, que se destinam a mercado interno, como arroz, milho, banana, mandioca, tiveram suas áreas reduzidas, provocando também queda em sua produção. O segundo motivo é que, na década de 1970, teve início programa mais efetivo de apoio à agricultura estadual, através ảos órgãos responsáveis pelo setor, tais como os de assistência técnica (EMATER-ES, IBC e CEPLAC), pes quisa (EMCAPA), expansão da rede rodoviária e do programa de eletrificação rural, que possibilitam maior uso de insumos modernos e investimentos de infra-estrutura nos estabeleci mentos agrícolas.

1 Vale lembrar que, naquela década, ocorreu também expansão das áreas com pastagens e reflorestamento. A primeira foi estimulada pelos recursos do Conselho Nacional da Pacuäria de Corte - CONDEPE, com crédito subs tancial e juros reais negativos; a segunda, graças aos incentivos fis cais ao reflorestamento e aos financiamentos do Banco Nacional de Desen volvimento Econômico e Social - BNDES, bem como a facilidade à aquisi ção de terras, proporcionadas pelo Governo Estadual. 
Esta análise da agricultura estadual, nesse período, permite uma visão do comportamento do setor em resposta a estes estimulos e também possibilita orientação de novas políticas para a agricultura do Estado do Espírito Santo. 


\section{REVISÃO DE IITERATURA}

Nos estuāos realizados sobre desempenho e diferenças regionais de crescimento agrícola notam-se dois tipos distintos de análise. O primeiro diz respeito ao uso do modelo de metafunção de produção e o segundo se refere ao uso de indicadores que quantificam as fontes de mudanças na produção e na produtividade aquícola.

Com a estimativa da metafunção de produção, HAYAMI \& RUTTAN (1975) estudam as causas das diferenças na produtividade agrícola, entre nações. Partem do pressuposto de que as diferenças em produtividade da mão-de-obra, entre países, resultam de diferenças nos seguintes fatores: acumulação de recursos internos, insumos técnicos provenientes do setor não-agrícola, e capital humano. Aqueles autores con cluem que, para os países mais desenvolvidos e os menos desenvolvidos, cada categoria de fatores contribui, aproxima damente, com um terço, na explicação das diferenças em pro dutividade da mão-de-obra.

A nível nacional, para analisar as diferen ças regionais da produção e produtividade da agricultura bra sileira, THOiMPSON (1974) utilizou dados do Censo Agropecuá rio de 1970, para dezoito estados e, também, uma metafunção produção. Dentre as várias conclusões obtidas naquele estudo, uma é a de guve educação, força de trabalho cientifico e fatores tradicionais (terra e mão-de-obra) têm participação mais ou menos igual, na explicação das diferenças em produ tividade agrícola, entre regiões do País. 
No que tange ao uso de indicadores que quantificam as fontes de crescimento do setor agrícola, vários trabalhos foram realizados no País.

Para fins de estudo do rendimento ou produ tividade da terra agrícola, no período 1933 a 1970 , MENDONÇA DE BARROS et alii (1976) usaram indice de produtividade da terra, decomposto em três efeitos: efeito tecnológico, efeito alocativo e efeito de interação. Aquele estudo concluiu que, para o País, o efeito interativo tem pouca participação e que somente os efeitos tecnológico e alocativo são importantes, no aumento do índice de produtividade da terra. Para a Região Nordeste, de um modo geral, constatararn que o crescimento observado da produtividade é baixo, o efeito tecnológico é nulo ọu negativo e, ainda, que a realocação da produção foi sempre em favor das culturas de menor índice de produtividade. Para a região Centro-Sul constataram que as taxas anuais de variação do indice de produtividade eram sempre positivas, no período, juntamente com o efeito tecnológico, sendo este geralmente alto, com excessão do período de 1950/55. O efeito alocativo é, em geral, favorável às culturas de maior produtividade.

O crescimento da agricultura brasileira também foi estudado no periodo de 1940/71 (MENDONÇA DE BARROS et alii, 1983). Naquele estudo, a taxa de crescimento da pro dução agrícola foi decomposta em três componentes: crescimento da produtividade de terra, crescimento da relação área/homem e crescimento da mão-de-obra. Aqueles autores verificaram que, até 1960, a taxa de crescimento da mão-de-obra foi fator importante, no aumento da produção e que, somente a partir da década de 1960, se nota aceleração nos ganhos da produtividade da terra e na relação área/homem. Para a Região Nordeste, até 1950, a participação da produtividade da terra foi negativa e constataram forte participação do aumento da relação área/homem e, somente, a partir de 1950, a par 
ticipação da produtividade da terra é positiva, mas ainda relativamente baixa, notando-se ainda aumento no crescimento da mão-de-obra. Para a Região Centro-sul, a participação dos componentes é praticamente equilibrada, destacando-se a produção por área e a relação área/homem.

A contribuição da área e do rendimento, para - crescimento da agricultura, nas unidades da Federação, foi pesquisada, para o período de 47/75, por VERA \& TOLLINI, 1979. Aqueles autores mostraram que, para o Brasil, a contribuição da área foi de $90 \%$ e do rendimento de $10 \%$, aproximadamente. A região que apresentou melhor desempenho do ren dimento foi o Sudeste, com cerca de $20 \%$, mas muito influenciada pelo Estado de São Paulo, cuja contribuição de rendi mento foi da ordem de $41 \%$. Para a Região Nordeste, a contribuição do rendimento foi negativa.

PATRICK (1975) estudou as fontes de cresci mento do setor de cultura, no Brasil, no período 1943 a 1969, utilizando o modelo shift-share, decompondo a variação na produção em quatro componentes: efeito-área, efeito-rendimen to, efeito-composição e efeito-localização. Naquele período, para o Brasil, ficou evidenciada a forte participação do efieto-área, no crescimento da produção, com maior uso do trabalho e formas tradicionais de capital. A Região sul foi aquela que apresentou melhor desempenho e maior efeito-rendimento.

Os resultados apresentados por PATRICK (1975), para o Brasil, não chegam a surpreender, levando-se em con sideração que a política adotada na época, para enfrentar o problema da oferta de alimentos, se concentraram na expansão da fronteira agricola, principalmente com ampliação da rede de transportes e melhoria da infra-estrutura de armazenamento (SMITH, 1983).

CUNHA \& DAGUER (1982) deram seqüência ao estudo das fontes de crescimento do setor de culturas, no Bra- 
sil, no periocio de 1969 até 1979, utilizando também a aná lise de shift-share. Aqueles autores concluiram que a área cultivada é ainda a principal fonte de crescimento do setor primário e que, dentre as chamadas culturas de campo, de maior expressão econômica, somente o aumento da produção do cacau foi fundamentalmente afetado pelo rendimento. Também frutas e hortaliças tiveram como principal fonte de crescimento o aumento da produtividade. O efeito-localização geagráfica da produção só foi importante para as culturas de café e sisal.

Em sintese, o desenvolvimento do setor agricola, até recentemente, baseou-se na expansão da área cul tivada. E importante observar que, tanto o modelo de shift -share, como os modelos utilizados por MENDONÇA DE BARROS et alii e VERA \& TOLLINI, quantificam as fontes de crescimento da agricultura, sem explicar ou identificar as variáveis que influenciam esses padrões de crescimento. O presente estudo também se utiliza da análise de shift-share, para medir o desempenho de parte do setor rural do Estado do Espirito Santo, analisando as diferenças regionais de cres cimento do subsetor de culturas. 


\section{MATERIAL E HETODOS}

Para medir as fontes de crescimento das principais culturas do setor rural do Estado do Espirito Santo, usa-se o modelo de shift-share, também denominado modelo diferencial-estrutural. Esse procedimento explica, de um lado, o crescimento das culturas, em termos de composição setorial das atividades na região e, de outro, analisa aquele crescimento, ligado a vantagens locacionais. Pode-se obter, assim, quatro fontes explicativas de variações na produção agrícola: (a) variações na área cultivada; (b) variações no rendimento das culturas; (c) variações no localização geográfica; e (d) mudanças na composição da produção regional.

O efeito-área mostra as mudanças na produção, decorrentes de variações na área cultivada que, geralmente, também levam a variações no emprego de mão-de-obra e de má quinas e implementos agricolas.

o efeito-rendimento e a alteração na produção que decorre de variações nos niveis de produtividade da terra, sendo, teoricamente, conseqüência de meihorias orga nizacionais, melhorias do capital humano, e introdução de novos insumos e técnicas de produção.

O efeito-composição reflete variações na pro dução decorrentes de mudanças na estrutura produtiva. Substituem-se culturas de menor rentabilidade, por unidade de área, por culturas de maior rentabilidade, por unidade de área.

o efeito-localização geográfica provoca mu - 
danças na produção, em decorrência de vantagens locacionais e traduz mudanças na produção decorrentes de mudanças na localização de culturas, entre unidades geográficas (municípios).

O modelo de shift-share pode ser descrito do seguinte modo. Para análise agregada no conjunto do Estado o período inicial é definido como 0 e o período final como t. Além disso, tem-se $i=$ município; $j=$ cultura; $Q_{t}=$ produção das culturas, no Estado, no periodo $t ; A_{t}=$ área to tal cultivada ảas 9 culturas, no Estado, no periodo $t ; A_{i . j t}=$ área total cultivada da j-ésima cultura, no i-ésimo município: $A_{i t}=$ área total cultivada, no i-ésimo município do Estado; $R_{i . j}=$ rendimento da j-ésima cultura, no i-ésimo município do Estado; $\alpha_{i j}=$ proporção da área total cultivada, no Estado, dedicada à j-ésima cultura, do i-ésimo município do Estado; $\beta_{i j}=$ proporção da área cultivada, da j-ésima cultura, no i-ésimo município do Estado; $\lambda_{i j}=$ proporção do i-ésimo mu nicípio na área cultivada do Estado, da j-ésima cultura; $\mathrm{p}_{\mathrm{jb}}=$ preço médio, para o Estado, do produto da j-ésima cultura.

Nesta análise, os preços dos produtos se fazem necessários, como redutores a unidades comuns, uma vez que se analisa a produção agregada das diferentes lavouras.

A produção estadual agragada, no período $\underline{t}$, ë definida como:

$Q_{t}=\sum_{i=1}^{n} \sum_{j=1}^{k}\left(\alpha_{i j} A_{t} A_{t} R_{i j} \quad P_{j_{b}}\right)^{\prime}$

e, no período 0 ,

$Q_{0}=\sum_{i=1}^{n} \sum_{j=1}^{k}\left(\alpha_{i j_{0}} \quad A_{0} R_{i j_{0}} \quad P_{j_{b}}\right)$

Se, do periodo inicial 0 , ao período $t$, a 
área cultivada aumenta, mantendo-se constantes rendimento, localização geográfica e composição de produto, a produção no período $t$ é dada por:

$Q_{t}^{*}=\sum_{i=1}^{n} \sum_{j=1}^{k}\left(\alpha_{i j_{0}} A_{t} R_{i j_{0}} P_{j_{b}}\right)$

Por outro lado, se área e rendimento variam, e a localização da produção e a estrutura do cultivo perma necem constantes, a produção, no período $t$, é dada por:

$Q_{t}^{* *}=\sum_{i=1}^{n} \sum_{j=1}^{k}\left(\alpha_{i j_{0}} A_{t} R_{i j_{t}} P_{j_{b}}{ }^{\prime}\right.$

Se a proporção da área cultuvada não se mo difica, a composição do produto dos municípios também não se modifica. Mas, variando área, produtividade e localização geográfica da produção, tem-se que o produto, no periodo $t$, dado por:

$$
Q_{t}^{* *}=\sum_{i=1}^{n} \sum_{j=1}^{n}\left(B_{i j_{0}} A_{i t} R_{i j} P_{j_{b}}{ }^{\prime}\right.
$$

A variação total na produção, do período inicial 0 , para o período final $t$, é dada por:

$$
\Omega_{t}-Q_{0}=\sum_{i=1}^{n} \sum_{j=1}^{k}\left(\alpha_{i j_{t}} A_{t} R_{i j} P_{j_{t}}\right)-\sum_{i=1}^{n} \sum_{j=1}^{k}\left(\alpha_{i j}{ }_{0}{ }^{A} R_{i j}{ }_{0}{ }^{P} j_{b}{ }^{\prime}\right.
$$

que também pode ser expressa por meio de:

$$
Q_{t}-Q_{0}=\left(Q_{t}^{*}-Q_{0}\right)+\left(Q_{t}^{* *}-Q_{t}^{*}\right)+\left(Q_{t}^{* *}-Q_{t}^{* *}\right)+\left(Q_{t}-Q_{t}^{* *}\right) \cdot \text { (VII) }
$$


onde $Q_{t}-Q_{0}=$ variação total na produção, entre 0 e $t$;

$$
\begin{aligned}
& Q_{t}^{*}-Q_{0}=\text { efeito-área; } \\
& Q_{t}^{* *}-Q_{t}^{*}=\text { efeito-rendimento; } \\
& Q_{t}^{* *}-Q_{t}^{* *}=\text { efeito-localização geográfica; } \\
& Q_{t}-Q_{t}^{* *}=\text { efeito-perfil da produção. }
\end{aligned}
$$

Maiores detalhes sobre a análise de shift share podem ser encontradas, por exemplo, no estudo de KAL BACHER, 1979. Exemplos de aplicações e discussões pormeno rizadas de aspectos mais especificos deste tipo de análise são encontradas, inter alia em CURTIS, 1972; GREEN \& ALLAWAY, 1985, e LEDEBUR \& MOOMAW, 1983.

$\mathrm{Na}$ análise municipal, para um conjunto de culturas, permanecem somente efeito-área, efeito-rendimento e efeito-composição e torna-se nulo o efeito-localização geográfica da produção.

Também nessa análise ë necessário utilizar-se os preços, como redutores da unidades comuns, uma vez que se analisa um conjunto de culturas.

A produção no período $t$, no i-ésimo municí pio é dada por:

$Q_{i t}=\sum_{j=1}^{k}\left(A_{i j t} R_{i j t} P_{j_{b}}\right)$

e, no período 0 ,

$Q_{i 0}=\sum_{j=1}^{k}\left(A_{i j_{0}} R_{i j_{0}} P_{j_{b}}\right)^{\prime}$ 
Se, no município $i$, do periodo $t$ para periodo 0 , variar a área das culturas, permanecendo constantes o rendimento e a proporção das áreas cultivadas das culturas, a produção no período $t$ será:

$Q_{i t}^{A}=\sum_{j=1}^{k}\left(B_{i j_{0}} A_{i t} R_{i j_{0}} P_{j_{b}}\right)$

Variando-se a área com culturas e o rendimen to permanecendo constante, a proporção das áreas cultivadas, a produção no período $t$ será:

$Q_{i t}^{R}=\sum_{j=1}^{k}\left(B_{i j_{0}} A_{i t} R_{i j_{t}} P_{j_{b}}\right)$

Se ocorrer mudanças na área das culturas, no rendimento e também na proporção das áreas das culturas, a produção no período $t$ será:

$Q_{i t}=\sum_{j=1}^{k}\left(\beta_{i j} A_{i t} R_{i j} P_{j_{b}}\right)$

A mudança do produto do período 0 para o período $t$ será expressa por:

$Q_{i t}-Q_{i 0}=\sum_{j=1}^{k}\left(\beta_{i j_{t}} A_{i j} R_{i j_{t}} P_{j_{b}}\right)-\sum_{j=1}^{k}\left(\beta_{i j_{0}} A_{i 0} R_{i j_{0}} P_{j_{b}}\right)$

ou também:

$Q_{i t}-Q_{i 0}=\left(Q_{i t}^{A}-Q_{i 0}\right)+\left(Q_{i t}^{R}-Q_{i t}^{A}\right)+\left(Q_{i t}-Q_{i t}^{R}\right)$ 
em que $Q_{i t}-Q_{i 0}=$ variação total na produção do período 0 ao periodo $t$, no i-ésimo município;

$$
\begin{aligned}
& Q_{i t}^{A}-Q_{i 0}=\text { efeito-área; } \\
& Q_{i t}^{R}-Q_{i t}^{A}=\text { efeito-rendimento; } e \\
& Q_{i t}-Q_{i t}^{R}=\text { efeito-composição das culturas. }
\end{aligned}
$$

Na análise individual das culturas, no Es tado, o efeito-composição torna-se nulo, permanecendo somen-te o efeito-área, o efeito-localização geográfica da produção e o efeito-rendimento.

A quantidade produzida de uma cultura para 0 Estado, no período $t$ será:

$$
Q_{j t}=\sum_{i=1}^{n}\left(A_{i j} R_{i j}\right)
$$

e, no período 0 :

$$
Q_{j 0}=\sum_{i=1}^{n}\left(A_{i, j} \quad R_{i j_{0}}\right)^{\prime}
$$

Tivesse mudado a área cultivada igualmente em todos os municípios, nao ocorrendo mudanças no rendimento e na localização geográfica da cultura, o produto no período $t$, seria:

$$
\sum_{i=1}^{n}\left(\lambda_{i j_{0}} \quad R_{i j_{0}}\right) \text { onde } \lambda_{j . j}=\frac{A_{i j}}{A_{j}}
$$

Se mudar a área cultivada e também o rendi mento, e nao muảando a localização geográfica da cultura, a produção no período $t$, sera: 
$Q_{j t}^{R}=\sum_{i=1}^{n}\left(\lambda_{i j j_{0}} \cdot A_{j t} \cdot R_{i j_{t}}\right)$

Mas se mudar a área cultivada, o rendimento

e também a localização geográfica da cultura, o produto no período $t$ será:

$Q_{t}=\sum_{i=1}^{n}\left(\lambda_{i j} A_{j t} R_{i j}\right)$

A variação na produção da j-ésima cultura, do período 0 para o periodo $t$ será:

$\Omega_{j t}-Q_{j 0}=\sum_{i=1}^{n}\left(\lambda_{i j_{t}} A_{j t} R_{i j_{t}}\right)-\sum_{i=1}^{n}\left(\lambda_{i j_{0}} A_{j 0} R_{i j_{t}}\right)$

que, ainda, pode ser expressa por meio de:

$Q_{j t}-Q_{j 0}=\left(Q_{j t}^{A}-Q_{j 0}\right)+\left(Q_{j t}^{R}-Q_{j t}^{A}\right)+\left(Q_{j t}-Q_{j t}^{R}\right)$

nas quais $Q_{j t}-Q_{j 0}=$ variação total na produção da cultura $j$ do período 0 ao período $t_{\text {; }}$

$Q_{j t}^{A}-Q_{j 0}=$ efeito-área;

$Q_{j t}^{R}-Q_{j t}^{A}=$ efeito-rendimento; e

$\begin{aligned} Q_{j t}-Q_{j t}^{R}= & \text { efeito-localização geográfica da pro- } \\ & \text { dução. }\end{aligned}$

Os dados básicos usados nas análises, refe rentes a área, rendimento e produção, são aqueles publicados por FIBGE, 1972; FIBGE, 1973; FIBGE, 1974; FIBGE, 1977;FIBGE, 1979; FIBGE, 1980; FIBGE, 1982; FIBGE, 1983; e FIBGE, 1984. Os dados efetivamente utilizados de área, rendimento e pro - 
dução nas análises sao médias geométricas trianuais, centradas em 1970, 1975 e 1980. Os dados básicos de preços de produtos agrícolas são os publicados por FGV, 1980; FGV, 1981 ; e FGV, 1982. Os dados de preços efetivamente utilizados são médias geométricas trianuais, centradas em 1980, de preços deflacionados pelo indice geral de preços da conjuntura econômica, corn base 1977 = 100 (FGV, 1982). 


\section{ANÁLISE DOS RESULTADOS}

Os resultados das análises de shift-share, a nível de município e estudo dos efeitos de área, rendimentos e composição e localização, sobre a taxa de crescimento do produto, são ap̣resentados nas Tabelas 1, 2 e 3 .

Nos períodos considerados (1970-75-80), efetivamente, observam-se mudanças acentuadas, tanto na área cultivada, como no rendimento físico das culturas e na com posição do oroduto agrícola. Assim; na década de 1970, a área cultivada com culturas apresentou taxa geométrica de crescimento negativo, da ordem de $0,75 \%$, ao ano, ao passo que o rendimento médio cresceu segundo taxa geométrica de 5,3\%, ao ano. O perfil da produção agrícola, que era composto prin cipalmente por lavouras orientadas para mercado interno (arroz, feijão, milho, mandioca, banana, tomate, canal, no inicio da década, passou a ser formado, principalmente, vor lavouras orientadas para mercado de exportação, como café e cacau, no final da década.

Os resultados obtidos nesta análise conjunta, de dados do setor agrícola do Estado do Espirito Santo, se contrastam com resultados obtidos em estudos anteriores (CUNHA \& DAGUER, 1982; IGREJA, 1982; PATRICK, 1975; VERA FILHO \& TOLLINI, 1979). O primeiro destaque se refere à importāncia relativa de mudanças no rendimento de culturas, na determinação da taxa de crescimento do produto. No presente estudo, os resultados evidenciam forte influência do rendi mento, maior mesmo que o da área cultivada sobre o produto. 
Pela Tabela 3, se não se alterasse a ärea cultivada, a composição e a localização das culturas e melhoria do rendimento teria contribuído em 3,58 a.a. no aumento da produção.

Isto não foi observado naquelas pesquisas anteriores, realizadas em outras áreas do País. Uma expli cação plausivel para esta discrepância é a de que, na década de 1970, ter-se-ia sentido o efeito das politicas de incentivo à modernização, como a expansão dos serviços de exten são rural e de crédito subsidiado, que possibilitaram o cres cimento do uso de insumos modernos, como fertilizantes, de fensivos e sementes melhoradas. Na década de 1970, os contratos de crédito rural, para o setor de culturas, cresceram a uma taxa de 13,5\% a:a. (BANCO CElv̄TRAL, 1977). Os efeitos dessas politicas, sobre a predutividade dos fatores terra, capital e trabalho, foi investigado por CIDADE DE ARAÚJO(1980), - qual constatou que os produtores usuários de crédito fa ziam melhor uso dos recursos e obtiam melhores resultados financeiros do que seus contrapartes, os produtores não usuá rios de crédito. Se destaca pelo efeito-rendimento alto, vários municipios, que convém fazer um breve comentário sobre eles. O município de Linhares se caracteriza por uma topo grafia plana, que facilita o uso de tecnologia mecânica e quimica principalmente em culturas como arroz, feijão, mandioca, milho e cacau.

Os municipios como Barra de São Francisco, Domingos Martins, Itaguaçú, Santa Tereza, Iúna, Castelo, Jerônimo Monteiro e Muqui se caracterizam por pequenas e médias propriedade e por uma topografia irregular, restando como alternativas ao produtor para incremento da produção a melho ria do rendimento.

O segundo aspecto diz respeito à importância da mudança na comóosição das culturas, na determinação da taxa de crescimento do produto agricola. Verifica-se no pre - 
TABELA 1: Resultados da Análise de shift-share dos Efeitos de Área, Rendimento e Composição sobre a Taxa de Crescimento do Produto Agrícola, Estado do Espirito Santo, 1970-1975.

\begin{tabular}{|c|c|c|c|c|c|}
\hline \multirow{2}{*}{ Nunicipio } & \multirow{2}{*}{$\begin{array}{l}\text { Taxa Anual } \\
\text { de } \\
\text { Crescimento }\end{array}$} & \multicolumn{4}{|c|}{ Efeito } \\
\hline & & Area & Rendimento & Composição & $\begin{array}{l}\text { Loc. } \\
\text { Geograáf. }\end{array}$ \\
\hline Ecoporanga & $-10,6$ & $-7,632$ & $-3,604$ & 0,742 & $\cdots$ \\
\hline Itucurici & $-19,4$ & $-2,134$ & $-16,878$ & $-0,194$ & $\ldots$ \\
\hline Baixo Guanåũ & 1,9 & 8,189 & $-0,133$ & 6,137 & $\ldots$ \\
\hline B.S. Francisco & 8,5 & 0,51 & 6,29 & 1,615 & $\ldots$ \\
\hline Ilantenópolis & 4,0 & $-2,52$ & 3,68 & 2,84 & $\ldots$ \\
\hline Nova Venécia & 6,0 & 4,14 & 3,42 & $-1,62$ & $\ldots$ \\
\hline Aracruz & $-7,6$ & $--12,008$ & 1,52 & 2,812 & $\ldots$ \\
\hline C. Barra & $-10,6$ & $-9,646$ & $-2,226$ & 1,378 & $\ldots$ \\
\hline Fundão & $-1,6$ & $-0,896$ & 2,176 & $-2,864$ & $\ldots$ \\
\hline Iinhares & 8,1 & $-8,343$ & 16,038 & 0,405 & $\ldots$ \\
\hline São Mateus & 5,9 & 2,655 & 0,295 & $-2,391$ & $\ldots$ \\
\hline Afonso Cláudio & $-1,7$ & $-1,479$ & $-2,227$ & 2,023 & $\ldots$ \\
\hline Alfredo Chaves & 1,7 & $-2,363$ & 2,091 & 1,972 & $\ldots$ \\
\hline Domingos Martins & 21,0 & 5,04 & 12,18 & 3,57 & $\ldots$ \\
\hline Ibiraçū & $-15,8$ & $-15,958$ & 0,158 & 0 & $\ldots$ \\
\hline Itaguaçú & $-9,4$ & $-13,348$ & 4,136 & $-0,094$ & $\ldots$ \\
\hline Santa Leoroldina & $-9,5$ & 3,265 & $-1,995$ & 0,76 & $\ldots$ \\
\hline Santa Tereza & 3,5 & $-2,555$ & 4,585 & 1,47 & $\ldots$ \\
\hline Cariacica & $-14,0$ & $-13,16$ & $-2,94$ & 2,24 & $\ldots$ \\
\hline Serra & 2,5 & 4,55 & $-3,15$ & 1,075 & $\cdots$ \\
\hline Viana & $-11,8$ & $-10,974$ & $-1,534$ & 0,708 & $\ldots$ \\
\hline Castelo & 7,8 & $-6,552$ & 15,444 & $-1,092$ & $\cdots$ \\
\hline Iúna & $-1,8$ & $-3,366$ & 2,376 & $-0,81$ & $\cdots$ \\
\hline Funiz Freire & $-3,7$ & $-1,258$ & $-3,552$ & 1,11 & $\cdots$ \\
\hline Alegre & $-6,4$ & $-2,112$ & $-3,136$ & $-1,024$ & $\cdots$ \\
\hline Apiacá & $-.5,2$ & $-4,004$ & $-2,704$ & 1,56 & $\ldots$ \\
\hline C. Itapemirim & $-4,4$ & $-1,232$ & $-3,564$ & 0,396 & $\ldots$ \\
\hline Guaçuí & 3,3 & $-1,188$ & 2,97 & 1,518 & $\cdots$ \\
\hline J. Monteiro & $-7,2$ & $-3,24$ & $-2,808$ & $-1,03$ & $\ldots$ \\
\hline Mimoso do Sul & $-7,9$ & $-3,318$ & $-5,056$ & 0,474 & $\ldots$ \\
\hline Muqui & 9,0 & $-3,69$ & $-12,15$ & 0,54 & $\ldots$ \\
\hline São J. Calçado & 10,4 & 0,832 & 8,528 & 0,936 & $\ldots$ \\
\hline Anchieta & $-19,5$ & $-18,915$ & $-0,975$ & 0,585 & $\ldots$ \\
\hline Guarapari & 3,60 & 0,036 & 3,168 & 0,324 & $\ldots$ \\
\hline Iconha & $-0,70$ & $-4,214$ & 0,014 & $-3,493$ & $\ldots$ \\
\hline Itapemirjm & 0,24 & 1,8024 & 5,8008 & 4,2384 & $\ldots$ \\
\hline Rio N. do Sul & $-12,2$ & $-7,564$ & $-2,44$ & $-2,074$ & $\ldots$ \\
\hline Estado & $-0,5$ & $-3,98$ & 3,03 & 1,1 & $-6,0$ \\
\hline
\end{tabular}

FONIES: FIBGE, 1971; FIBGE, 1972; FIBGE, 1973; FIBGE, 1976; FIBGE, 1977 e EIBCE, 1978. 
TABELA 2: Resultados da Análise de shift-share dos Efeitos de Ârea, Rendimento e Composição sobre a Taxa de Crescimento do Produto Agrícola, Estado do Espirito Santo, 1975-1980.

\begin{tabular}{|c|c|c|c|c|c|}
\hline \multirow{2}{*}{ Município } & \multirow{2}{*}{$\begin{array}{l}\text { Tasa Anual } \\
\text { de } \\
\text { Crescimento }\end{array}$} & \multicolumn{4}{|c|}{ Efeito } \\
\hline & & Ärea & Rendimento & Conæِ مaşiç & $\begin{array}{l}\text { Ioc. } \\
\text { Geggráf. }\end{array}$ \\
\hline Ecoporanga & $-0,2$ & $-1,80$ & $-0,16$ & 1,76 & $\cdots$ \\
\hline Mucurici & 26,0 & 8,10 & 16,90 & 0,52 & $\ldots$ \\
\hline Baixo Guandú & 9,9 & 4,26 & 6,04 & $-0,39$ & $\ldots$ \\
\hline B.S.Francisco & 7,2 & 3,67 & 3,38 & 1,10 & $\ldots$ \\
\hline Colatina & 3,0 & 2,31 & $-0,24$ & 0,90 & $\ldots$ \\
\hline Mantenópolis & 8,6 & $-2,75$ & 5,00 & 6,40 & $\ldots$ \\
\hline Nova Venécia & 3,5 & 4,20 & 1,20 & 0,52 & $\ldots$ \\
\hline Aracruz & $-14,0$ & $-14,42$ & 2,24 & $-1,70$ & $\ldots$ \\
\hline C Barra & 2,5 & 0,63 & 0,77 & 1,05 & $\ldots$ \\
\hline Fundão & $-0,2$ & $-0,63$ & 0,61 & $-0,17$ & $\ldots$ \\
\hline Linhares & 9,9 & 5,15 & 6,04 & $-1,40$ & $\cdots$ \\
\hline São Mateus & $-7,7$ & $-6,94$ & 0,31 & $-1,83$ & $\ldots$ \\
\hline Afonso Cláudio & 7,6 & $-0,68$ & 3,12 & 5,10 & $\cdots$ \\
\hline Alfredo Chaves & $-0,7$ & 1,17 & $-2,20$ & 0,47 & $\because$ \\
\hline Doringos Martins & $-6,8$ & $-8,43$ & 5,17 & $-3,53$ & $\cdots$ \\
\hline Ibiraçú & $-1,6$ & $-6,91$ & 2,53 & 2,77 & $\cdots$ \\
\hline Itaguaçú & 21,5 & 3,22 & 7,10 & 10,75 & $\cdots$ \\
\hline Santa Leopoldina & 6,8 & $-1,50$ & 2,58 & 5,64 & $\cdots$ \\
\hline Santa Tereza & 10,5 & 2,20 & 4,10 & 3,99 & $\cdots$ \\
\hline Cariacica & $-6,1$ & $-2,19$ & 5,37 & 1,46 & $\cdots$ \\
\hline Serra & $-1,4$ & $-3,55$ & 2,25 & 0,09 & $\cdots$ \\
\hline Viana & $-6,1$ & 1,46 & $-8,29$ & 0,67 & $\cdots$ \\
\hline Castelo & 13,9 & $-0,55$ & 7,64 & 6,67 & $\cdots$ \\
\hline Iúna & 36,7 & 6,97 & 22,38 & 6,97 & $\cdots$ \\
\hline Ifuniz Freire & 11,0 & $-3,41$ & 6,60 & 7,81 & $\because$ \\
\hline Alegre & 6,6 & $-0,53$ & 4,62 & 2,44 & $\because \cdots$ \\
\hline Apiacá & $-5,3$ & $-6,31$ & 1,00 & $-0,00$ & $\cdots$ \\
\hline C. Itapemirim & 18,5 & 0,37 & 17,02 & 0,92 & $\cdots$ \\
\hline Guaçuí & 8,4 & $-1,68$ & 6,97 & 3,02 & $\cdots$ \\
\hline J. Monteiro & 20,6 & 7,62 & 12,15 & 0,62 & $\cdots$ \\
\hline Mimoso do Sul & 1,4 & $-2,04$ & 4,07 & $-0,62$ & $\cdots$ \\
\hline Iuqui & 3,6 & 0,93 & 0,72 & 1,87 & $\cdots$ \\
\hline São J . Calçado & $-2,2$ & $-4,97$ & 1,85 & $-0,90$ & $\because \cdots$ \\
\hline Anchieta & $-6,1$ & $-5,98$ & 2,56 & 2,62 & $\cdots$ \\
\hline Guarapari & $-4,20$ & $-4,75$ & 0,00 & 0,50 & $\cdots$ \\
\hline Iconha & $-5,00$ & $-3,00$ & $-1,05$ & $-0,85$ & $\cdots$ \\
\hline Itapemirim & 12,77 & 4,45 & 9,14 & $-1,02$ & $\cdots$ \\
\hline Rio N. äo Sul & 3,99 & 1,05 & 1,40 & 1,40 & $\cdots$ \\
\hline Estado & 7,9 & 1,26 & 4,50 & 4,4 & $-2,3$ \\
\hline
\end{tabular}

FONTES: FIBGE, 1976; FIBGE, 1977; FIBGE, 1978; FIBGE, 1981; FIBGE, 1982 e FIBGE, 1983. 
TABELA 3: Resultados da Análise de shift-share dos Efeitos de Ârea, Rendimento e Composição sonre a Taxa de Crescimento do Produto Agricola, Estado do Espirito Santo, 1970-1980.

\begin{tabular}{|c|c|c|c|c|c|}
\hline \multirow[b]{2}{*}{ Município } & \multirow{2}{*}{$\begin{array}{c}\text { Taxa Anual } \\
\text { de } \\
\text { Crescimento }\end{array}$} & \multicolumn{4}{|c|}{ Efeito } \\
\hline & & Área & Rendimento & Cormosição & $\begin{array}{c}\text { Loc. } \\
\text { Geogrä. }\end{array}$ \\
\hline Ecoporanga & $-5,5$ & $-4,68$ & $-1,6$ & 0,83 & $\ldots$ \\
\hline Mucurici & 0,8 & 5,4 & $-4,5$ & $-0,09$ & $\ldots$ \\
\hline Baixo Guandú & $-3,8$ & $-2,0$ & 3,0 & 2,8 & $\ldots$ \\
\hline B.S. Francisco & 7,8 & 1,7 & 4,5 & 1,5 & $\cdots$ \\
\hline Colatina & 1,3 & $-0,8$ & 2,3 & $-0,12$ & $\cdots$ \\
\hline Mantenópolis & $-6,3$ & $-2,1$ & 3,5 & 4,8 & $\ldots$ \\
\hline Nova Venécia & 4,8 & 4,1 & 0,3 & 0,3 & $\ldots$ \\
\hline Aracruz & $-10,8$ & $-12,3$ & 1,7 & $-0,2$ & $\ldots$ \\
\hline C. Barra & $-4,0$ & $-4,2$ & $-0,7$ & 1,0 & $\ldots$ \\
\hline Fundão & $-0,9$ & $-0,7$ & 1,6 & $-1,7$ & $\ldots$ \\
\hline Linhares & 9,0 & $-2,2$ & 11,2 & $-0,1$ & $\ldots$ \\
\hline São Mateus & $-1,1$ & $-1,7$ & 0,7 & $-0,02$ & ... \\
\hline Afonso Cláudio & 2,8 & $-0,9$ & 0,1 & 3,6 & $\ldots$ \\
\hline Alfredo Chaves & 0,5 & $-0,7$ & $-0,8$ & 2,1 & $\ldots$ \\
\hline Domingos Martins & 6,17 & $-0,9$ & 8,8 & $-1,7$ & $\ldots$ \\
\hline Ibiraçú & $-9,0$ & $-10,6$ & 0,8 & 0,7 & $\ldots$ \\
\hline Itaguaçú & 4,9 & $--3,5$ & 4,0 & 4,4 & $\ldots$ \\
\hline Santa Leopoldina & $-1,7$ & $-4,3$ & 0,4 & $-2,2$ & $\ldots$ \\
\hline Santa Tereza & 6,9 & $-0,2$ & 4,3 & 2,6 & $\ldots$ \\
\hline Cariacica & $-10,2$ & $-8,5$ & $-0,7$ & $-0,8$ & $\ldots$ \\
\hline Serra & 0,7 & 0,5 & $-0,4$ & 0,5 & $\ldots$ \\
\hline Viana & $-9,0$ & $-5,8$ & $-2,0$ & $-1,0$ & $\ldots$ \\
\hline Castelo & 10,2 & $-2,0$ & 10,3 & 1,9 & $\ldots$ \\
\hline Iúna & 15,8 & 2,1 & 10,0 & 3,5 & $\ldots$ \\
\hline Wuniz Freire & 3,4 & $-2,3$ & 1,7 & 4,0 & $\ldots$ \\
\hline Alegre & $-0,07$ & $-1,3$ & 0,6 & 0,6 & $\ldots$ \\
\hline Apiacá & $-5,2$ & $-5,2$ & $-0,6$ & 0,6 & $\ldots$ \\
\hline C. Itapemirim & 6,4 & $-0,2$ & 5,3 & 1,3 & $\ldots$ \\
\hline Guaçuí & 2,5 & $-0,5$ & 1,9 & 1,1 & $\ldots$ \\
\hline J. Monteiro & 5,8 & 2,7 & 4,1 & 1,0 & $\ldots$ \\
\hline Imimoso do Sul & $-3,4$ & $-2,8$ & $-0,5$ & 0,2 & $\ldots$ \\
\hline isuqui & 6,3 & $-1,4$ & 6,2 & 1,4 & .. \\
\hline São J. Calçado & 3,9 & $-1,6$ & 4,4 & 1,2 & $\cdots$ \\
\hline Anchieta & $-13,0$ & $-13,0$ & 0 & 0 & $\cdots$ \\
\hline Guarapari & $-3,9$ & $-2,6$ & $-0,04$ & 1,2 & $\cdots$ \\
\hline Iconha & $-2,9$ & $-3,5$ & 0,50 & 0,2 & $\ldots$ \\
\hline Itapenirim & 5,3 & 3,1 & 0,8 & 2,4 & $\ldots$ \\
\hline Rio N. do Sul & $-4,5$ & $-3,1$ & $-0,4$ & $-0,9$ & $\cdots$ \\
\hline Estado & 3,5 & $-1,4$ & 3,4 & 2,5 & $-1,0$ \\
\hline
\end{tabular}

FONIES: FIBGE, 1971; FIBGE, 1972; FIBGE, 1973; FIBGE, 1981; FIBGE, 1982 e FIBGE, 1983. 
sente estudo, maior importância relativa de mudanças na composição do produto agrícola agregado, ao conträrio do que foi constatado em pesquisas anteriores (CUNHA, 1982; IGREJA, 1982 ; e PATRICK, 1985). Na década de 1970, as fortes modi ficações observadas na composição do produto, com crescente expansão da área cultivada corn café e relativa retração das áreas dos produtos de mercado interno, se deveram, além da elevação de preço no mercado internacional de café, a estímulos diferenciados oferecidos pelo governo, à produção orientada para mercado externo como, por exemplo, as politi cas creditícias, cambial e de pesquisa e assistēncia técnica, que favoreceram de modo diferencial os produtos de exporta ção (MELLO, 1984).

Essa mudança na composição do produto, na agricultura do Espirito Santo, no periodo de 1970-80, foi importante para o crescimento do produto, pois o café foi reimplantado com novos padrões tecnológicos, fazendo com que municípios como Iúna, Castelo, Mantenópolis, Itaguaçú, Muniz Freire, onde esta lavoura mais se expandiu, acusassem as maiores taxas de crescimento, sendo o efeito-composição um dos principais responsáveis por essas taxas.

Vale lembrar que o conjunto de mudanças observadas na produtividade e no perfil do produto tem contribuido de modo positivo e significativo para o crescimento do produto e parece aumentar a desigualdade da distribuição da renda no meio rural, no Brasil (HOFFMAN \& KAGEYAMA, 1984).

Outro ponto importante a observar é o efeito -área negativo. Naquela década, se mantivesse constante o rendimento, a composição e a localização geográficá da produção a redução na área plantada dessas culturas causaria uma queda na produção de $1,4 \%$ a.a.

A queda das áreas cultivadas como essas culturas, se deve à expansão das áreas com pastagens e reflorestamento, como mostram os resultados das pesquisas realizadas 
por SALGADO, 1982 e MOTTA, 1982. A pecuāria bovina capixaba foi beneficiada pelos recursos do Conselho Nacional da $\mathrm{Pe} \mathrm{-}$ cuária - CONDEPE, incentivando a formação de pastagens com creaito barato e farto, chegando essa atividade em 1975 a absorver 54,1\% do valor do crédito rural do Estado, tornando -se assim o responsav́el pelo efeito área negativo em todos os municípios do Espírito Santo na década de 1970.

O reflorestamento foi outra atividade que se expandiu graças aos recursos estatais, através dos incentivos fiscais ao reflorestamento, através dos decreto-leis 5.106 de 02 de setembro de 1960 e 1.134 de 16 de novembro de 1970. As áreas com florestas artificiais em 1970 era de 25.119 ha passando em 1980 para 143.148 ha, crescendo a uma taxa anual na década de $19 \%$

Essas florestas são compostas de $98 \%$ com eucaliptos para atender a fábrica de celulose, sendo os recursos do decreto-lei acima citado responsáveis por 83\% da ārea total de florestas implantadas no Estado. Essa atividade explica os efeitos-áreas negativos nos municípios de Conceição da Barra, Aracruz, Ibiraçú, são Mateus e Anchiera.

Pela Tabela 5 se observa naquela década no Espirito Santo que as culturas de mercado interno, como ar-. roz, mandioca, milho, banana acusaram taxas negativas de crescimento, com o feijão, mantendo o seu nível de produção. Ao passo que culturas energéticas como a cana e de exportação como café e cacau tiveram relativamente elevadas taxas de crescimento em sua produção.

Segue-se na discussão pormenorizada de mu-danças observadas nas estruturas de produção das lavouras especificas incluídas no estudo, as quais podem ajudar na exp̣licação, pelo menos em parte, das mudanças constatadas nas análises de shift-share apresentadas nas Tabelas 4,5 e 6 . 


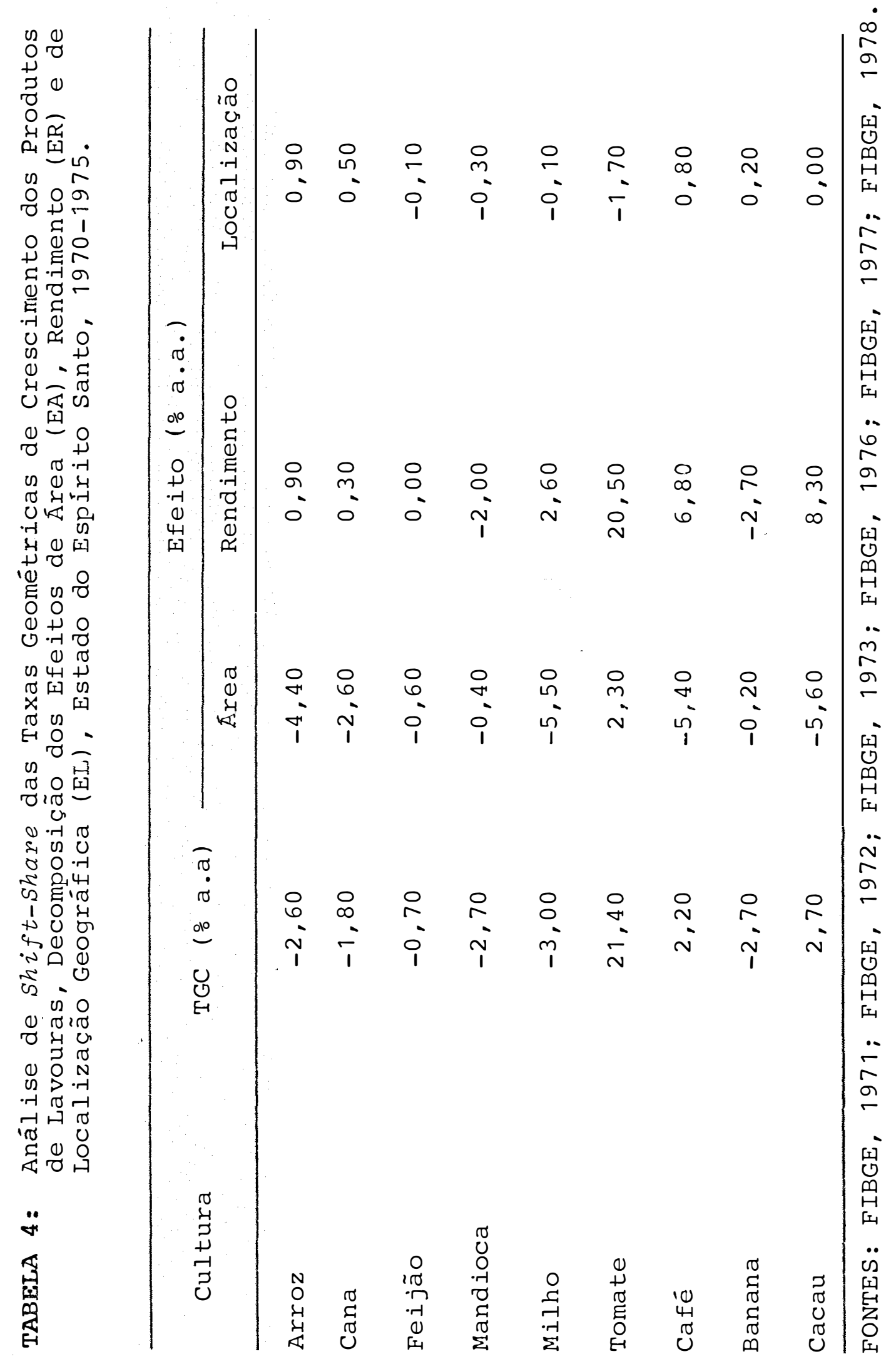




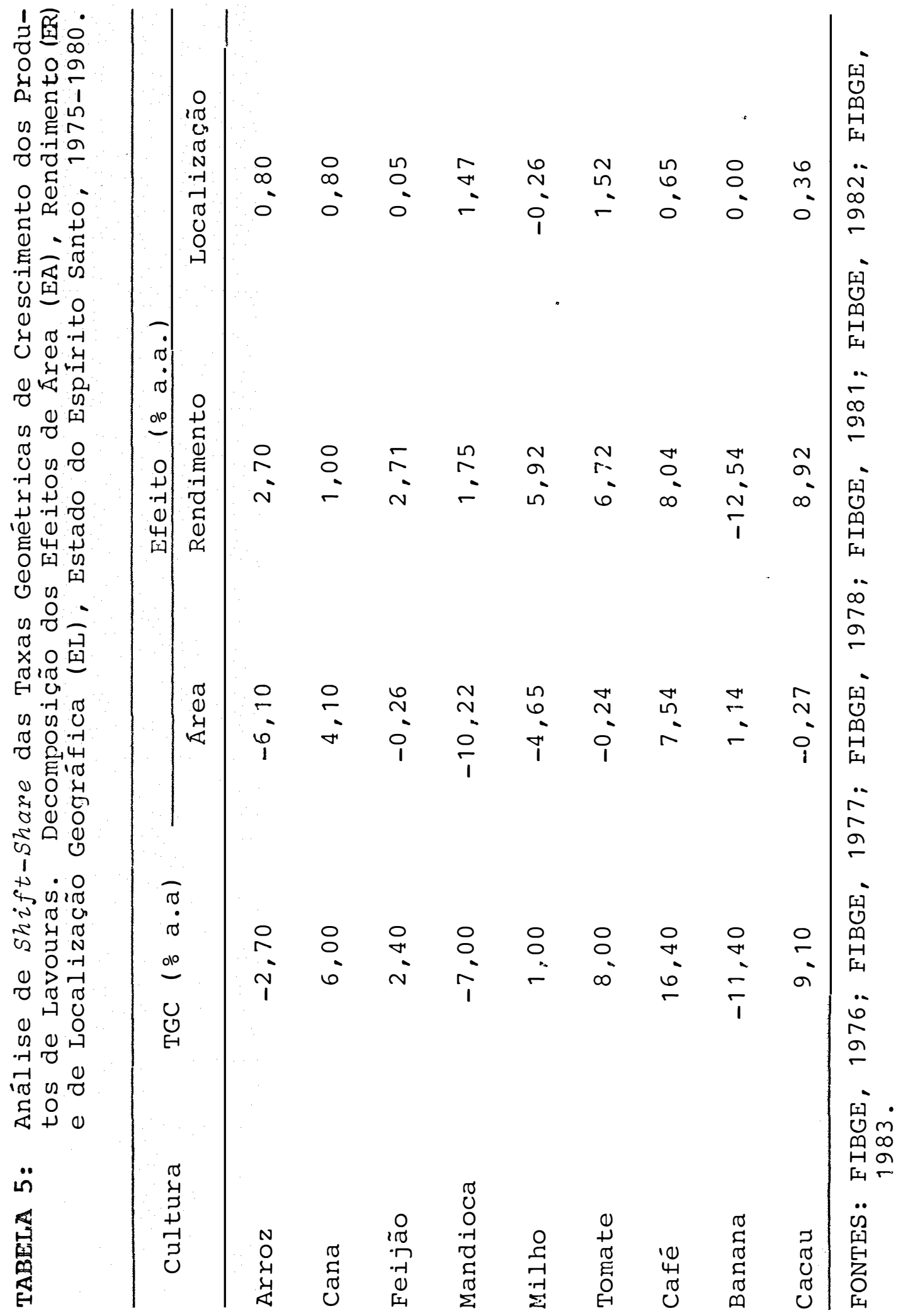


25.

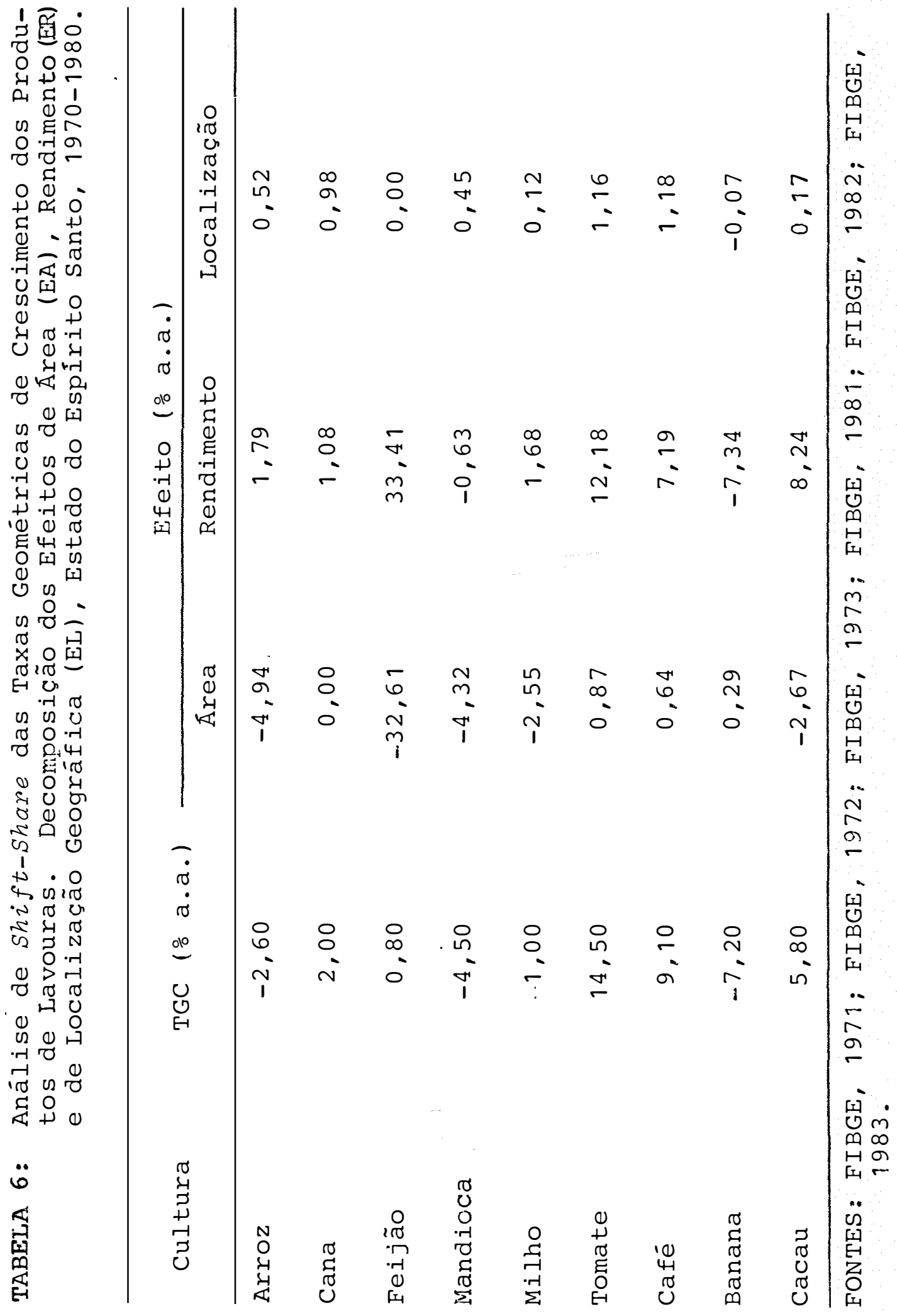


A lavoura de arroz é encontrada em todo território estadual, mas se concentra nos municípios de Barra de São Francisco, Pancas, São Gabriel da Palha, Itapemirim, Presidente Kennedy, Afonso Cláudio, Itaguaçú e Mimoso do Sul.

Até final da década de 1960, esta lavoura não era conduzida cón maior aprimoramento técnico, nem era especialmente estimulada por politicas agrícolas especificas. No final daquela década e no início da década de 1970, em de corrência do Programa de Erradicação de Cafezais, é que ela passou a receber maior atenção por parte das instituições pú blicas. O número de contratos de crédito para a lavoura de arroz acusou aumento, na década de 1970, da ordem de 8,6\% a. a., passando de 317 em 1970, para 1862, em 1980. Contudo, a participação desta lavoura no valor do crédito rural total, que em 1970 era da ordem de 4,6\% passou em 1980, para apenas $1,6 \%$ daquele valor total.

A assistência técnica aos produtores de arroz, prestada pela ENATER-ES, em 1970, apresentou taxa de atendimento de 5,4\% de área plantada com esta lavoura, passando, em 1980, para 50\% dessa área total.

A política de crédito subsidiado, aliada à de extensão rural, tenderam favorecer a aquisição de insumos agrícolas modernos, como sementes melhoradas, fertilizantes e defensivos. Esse processo de difusão tecnológico também foi, em algum grau, estimulado pelo trabalho da EMCAPA, ao propor pacote tecnológico tendente à maior produtividade. Contudo, nota-se que parte dos proutores não utilizam aquele conjunto de tecnologias proposto, limitando-se a algumas tecnologias nele embutidas, fazendo com que o efeito-rendi mento fosse de somente 1,8\% a.a.

Ao longo da década de 1970, o preço real desse produto também foi pouco estimulante, quando comparado ao de outros produtos, apresentando taxa de crescimento relati- 
vamente baixa.

As áreas produtoras de cana-de-açúcar do Estado, até 1980, concentram-se na Região Sul, sendo os muni cípios de Presidente Kennedy, Itapemirim, Castelo e Cachoeiro de Itapemirim os principais produtores desta gramínea.

A cana produzida nos dois primeiros municí pios citados é transformada na usina são Miguel e a dos dois últimos, na usina Paineiras. A produção de cana das peque nas propriedades dos outros municípios é orientada para au to-consumo e para produção de forragens, ou se destina "à transformação em aguardente, em pequenas unidades fabrís denominadas a lambiques.

A lavoura de cana-de-açúcar é atividade que, até meados da década de 1970, se apresentava com baixo nível tecnológico, sendo praticamente inexistentes as práticas de conservação de solo, mecanização e fertỉização química.

Somente a partir de 1975 é que essa atividade apresentou tendência de elevação dos níveis de produção e produtiviảade, graças em parte ao melhor desempenho técnico das usinas de açúcar, as quais passaram a contar com a con tribuição da pesquisa pública e da orientação técnica do PIXNALSUCAR, que passou a desenvolver trabalho cooperativo com estas empresas, contribuindo para elevação dos níveis tecnológicos da produção agrícola e agroindustrial e em parte responsável pelo efeito-rendimento de 1,08\% .

No que tange a grande adoção de novas tecno-logias, como cultivares mais resistentes às doenças, ferti lizantes, defensivos, máquinas e equipamentos agrícolas, a Secretaria da Agricultura do Estado, divide os produtores de cana em três grupos, a saber: (a) utilizando técnicas modernas de cultivo. Fazem parte desse grupo os fornecedores das usinas, cuja produtividade se situa em torno de 45 t/ha; (b) cultivando cana...de-açúcar de maneira tradicional. Aqui se situam os produtores que orientam a produção para fabricação 
de aguardente, obtendo rendimentos da ordem de 21 t/ha; e (c) mesclando técnicas tradicionais e modernas, e obtendo produtividade da ordem de $35 \mathrm{t} / \mathrm{ha}$.

Quanto ao valor do crédito rural fornecido aos produtores desta gramínea, de um modo geral, na década de 1970, essa atividade teve baixa participação no volume total de crédito rural, girando em torno de 1,0\%. Naquele período, o preço real do produto também foi relativamente baixo e cresceu a uma taxa geometricamente média de 1,8\% ao ano, aproximadamente.

O feijão é uma das lavouras mais dissemina das entre os municípios do Estado e que se encontra distri buída de forma bastante homogênea. A produção de feijão se destina basicamente à subsistência e, gerälmente, a lavoura é cultivada de modo intercalar com milho e café. Essas ca .. racteristicas tem contribuido para a alta estabilidade ob servada, em termos de área plantada, durante a década de 1970.

A assistência técnica, prestada pela EMATERES, aos produtores desta leguminosa, evoluiu bastante, na década de 1970, e chegou a alcançar, em 1980, cerca de 40\% da área plantada, enquanto que, em 1970, somente 0,2\% daque-le total recebia assistência técnica. Para os produtores assistidos pela EMATER-ES, O uso de sementes melhoradas passou de aproximadamente $25 \mathrm{~kg} / \mathrm{ha}$, em 1970, para mais de $32 \mathrm{~kg} / \mathrm{ha}$, em 1980. O uso de fertilizantes nessa cultura passou de 44 $\mathrm{kg} / \mathrm{ha}$, em 1970, para $66 \mathrm{~kg} / \mathrm{ha}$, em 1980. O consumo de defensivos, passou de 0,3 kg/ha, em 1975, para 0,7 kg/ha, em 1980 .

A pouca utilização do benefício " de preços mínimos pelos produtores de feijão do Espírito Santo, além do preço de garantia relativamente baixo, se deve, pelo me nos em parte, aos seguintes fatores: (a) a produção é obtida em pequenas unidades produtoras e se destina principalmente a auto consumo, comercializando-se apenas pequenos exceden tes; e (b) a escassez de agências bancárias e de unidades ar- 
mazenadoras.

Quanto ao crédito rural para esta atividade nota-se que, em 1970, ele era da ordem de 0,8\% do vaior total do crédito concedido à agricultura, passando, em 1980 , para cerca de 3,3\% daquele total. O. número de contratos de crédito rural para os produtores de feijão cresceu a uma taxa de 27\% ao ano, passando de 456, em 1970, para 4.837, em 1980 .

O preço real do produto evoluiu uma taxa de 6,58 ao ano, o que constitui uma das maiores taxas de cres cimento, dentre os observadas para os nove produtos estuda ... dos.

A lavoura de mandioca encontra-se disseminada de maneira bastante homogênea no Estado. E exploração tradicional, conduzida principalmente por pequenos produto res, destinando-se tanto ao consumo humano, nas formas in natura e industrializada, como ao arraçoamento animal.

No Estado, o nível. tecnológico típico da cultura da mandioca ainda é relativamente baixo. As práticas de adubação e controle de pragas e doenças são praticamente inexistentes. As lavouras são encontradas, em sua quase totalidade, em terrenos amorrados ou montanhosos. As mani vas utilizadas no plantio são, em geral, oriundas de lavou ras do ano anterior, não se observando, em geral, critérios de seleção. Isso contribui para baixa produtividade, em relação à de outros Estados produtores. Por exemplo, em 1970, o rendimento no Estado era de $16,7 \mathrm{t} / \mathrm{ha}$, enquanto que em Santa Catarina ele era de 21,1 t/ha, aproximadamente.

Nos primeiros anos da década de 1970, visando a produção de pellets de mandioca para exportação, foi ins talada, na região Norte do Estado, a Indústria MAICAL - Mandioca Agroindustrial, cuja capacidade instalada de processamento é de ordem de 54.000 toneladas de raiz, por ano. 
A assistência técnica a essa cultura so se fez sentir a partir do ano de 1976, quando atingiu $2 \%$ da area total explorada com a lavoura. Em 1980 a assistênciatécnica chegou a alcançar 52\% daquele total. A EMATER-ES procurou, através do uso de manivas selecionadas e de defensi vos agricolas, aumentar os níveis de produtividade da lavoura, objetivando elevar a produção de matéria-prima para a unidade recém-instalada, bem como para pequenas indústrias da região. Para isso o mecanismo utilizado foi o crédito de custeio. O número de contratos de crédito para a lavoura de mandioca passou de 440, em 1970, para 1.156, em 1976, sendo que, neste último ano, ele representou cerca de 2,2\% do to tal do valor do crédito agrícola.

Com o aumento da produção da raiz e o não funcionamento da ināústria citada observou-se forte queda no preço do produto. A queda observada no preço real do produto desestimulou os produtores. Assim, observou-se um efeito -área de $-4,32 \% \mathrm{a} . \mathrm{a}$. e um efeito-rendimento praticamente nulo na década de 1970.

O milho também se encontra bastante disseminado em todos os municípios do Estado, existindo porém municipios que se destacam, como o de Afonso cláudio.

O milho é produzido geralmente nos pequenos estabelecimentos rurais e se destina à subsistência e à ma nutenção de criações domésticas, principalmente aves e suínos.

Até o início da década de 1970 as condições de cultivo do milho revelaram-se bastante precárias. Naquele período, eram freqüentes os plantios intercalares, com café, feijão, sugerindo baixo grau de especialização dos seus produtores. A adubação era prática observaủa em $10 \%$ da área plantada. Quase inexistente era o uso de defensivos. Contudo, cerca de 40\% dos produtores já usavam sementes melhora das.

A partir da década de 1970 , a atuação gover- 
namental, através da EMATER-ES e da EMCAPA, parece ter contribuído para melhoria do cultivo do milho, apresentado em efeito-rendimento de 1,68\% a.a.; compensando em parte a queda na área plantada.

A pesquisa estatal tem atuado no sentido de avaliar e indicar cultivares mais produtivos e adaptados às condições locais, utilizando para isso as estações experi mentais localizadas em diversas regiões agrícolas do Esta do.

A extensão rural intensificou o seu traba Iho para essa cultura, já que, em 1970, assistia 2,5\% da área plantada total chegando, em 1980, a assistir cerca de 40\% daquele total. Nessas áreas assistidas intensificou-se, em algum grau, o uso de sementes melhoradas, fertilizantes e defensivos agrícolas.

Se os resultados desses esforços, em termos de rendimento, não foram melhores, isto se deve às condiōes desfavoráveis ao cultivo da gramínea como a incidência da helmintosporiose, no triênio 1971-73, e a ocorrência de seca e excesso de chuva, ao longo do período 1974-1977.

Quanto ao uso de crédito rural, entre osprodutores de milho, constata-se que, no ano de 1970, foram registrados 2.940 contratos para custeio, representando $6,7 \%$ do total do crédito rural e, em 1980, esses contratos passaram para 4.427, mas sua participação caiu para 3,4\% do número total de contratos.

O tomate concentra-se na Região Serrana, a qual é responsável por 85\% da produção estadual. A produ ção dessa solanãcea cresceu a uma taxa de $14 \%$ a.a. e se destaca pelo alto efeito-rendimento de $12,18 \% \mathrm{a} . \mathrm{a}$.

Dentre as atividades agrícolas a tomaticultura é a que mais intensivamente é assistida pela EMATER-ES. Em 1970, somente 9,5\% da área total cultivada com tomate re- 
cebia assistência técnica. Em 1980, esta parcela cresceu para $82 \%$ daquele total. Constata-se que ela foi beneficiada por grande avanço tecnológico, com, generalizado emprego de novos cultivares, sementes selecionadas, fertilizantes, corretivos, defensivos, máquinas e equipamentos.

Na área assistida pelo serviço estadual extensão rural, o uso de fertilizantes passou de $554 \mathrm{~kg} / \mathrm{ha}$, em 1970-72, para 2,371 kg/ha, em 1979-80; o uso de defensivos evoluiu de $1,1 \mathrm{~kg} / \mathrm{ha}$ para $50 \mathrm{~kg} / \mathrm{ha}$, no mesmo período, e o emprego de mudas selecionadas passou de $6.901,5$ unidades/ha, em 1970-72, para 16.851,3 mudas/ha, em 1979-80. Essas mudas são de cultivares mais produtivos e adaptados às condições locais, como Koda, Angela, Yokota e Osama-2. Para alcançar estes progressos, os produtores contaram com auxilio dos serviços de crédito rural oficial.

A cultura do café, do ponto de vista histórico, tem sido a atividade mais importante da agricultura do Espirito Santo. Na década de 1960, ela contribuiu com cerca de $30 \%$ da renda estadual total.

No final da década de 1960, a péssima situa ção das lavouras, aliada à crise internacional do produto, foi posto em prática o chamado Plano de Renovação e Revigoramento de Cafezais. Entre os triênios de 1960-62 e 1970 72, foram erradicados 213.000 hectares da lavoura de café, através dos programas de erradicação contido naquele plano.

O referido plano envolveu também programas de plantio, produção de mudas, promoção do uso de insumos modernos e de aquisição de equipamentos para defesa sanitária. Através daquele plano recuperou-se a exploração cafeeira estadual, por meio de financiamento, entre os triênios de 197071 e 1930-81, de cerca de 127 milhões de covas de café, contribuindo assim para um efeito área e efeito-rendimento positivos de 0,64\% a.a, e 7,19\% a.a., respectivamente. 
O Plano de Renovação e Revigoramento de Cafezais previa, inicialmente, o plantio somente de variedades àa espécie arábica, em regiões situadas acima de $400 \mathrm{~m}$ de altitude. Porém, com a possibilidade do plantio variedades da espécie canephora, ocorreu a expansão da lavoura cafeeı̀ra em áreas mais baixas e mais quentes, alcançando áreas loca lizadas na Região Norte do Estado. Essa nova distribuição regional da lavoura, explica o efeito-localização de 1,13\% a.a.

Em 1970, a lavoura de café absorveu cerca de $15 \%$ dos contratos de crédito de custeio e $20 \%$ do montante de credito liberado. Em 1980, estas parcelas chegaram a $42 \%$ e $70 \%$, respectivamente.

Em, 1974, o crédito de investimento, para formação de nossas lavouras de café absorveu cerca de 13,7\% do montante total de crédito para investimento no subsetor de culturas. Em 1980, esta parcela atingiu 39,2\%, aproximada mente.

A assistência técnica à cafeicultura estadual é prestada pelo IBC, através do Serviço de Racionalização đa Cafeicultura - SERAC, disseminado nos principais municipios produtores, por meio de equipes de técnicos treinados e especializados na cultura. No final da década de 1970 estavam em funcionamento no Estado, doze destas unidades de assistên cia técnica à cafeicultura.

A cultura da banana se concentra principal mente nos municípios de Iconha, Alfredo Chaves, Anchieta,Domingos Martins e Linhares. Neste ültimo município, a bana neira é cultivada com o cacaueiro, para sombreamento deste.

Em geral, o nível tecnológico observado no cultivo da bananeira é baixo. A técnica do desbaste, de importância fundamental, é praticamente desconhecida pela maioria dos produtores, e as medidas fitossanitárias para combate aos inimigos naturais da cultura, como a broca e a fusa - 
riose, são adotadas em pequena escala. Cerca de 95\% dos bananais são encontrados em áreas com declividade superior a $30 \%$.

Estudo feito pela EllATER-ES, em 1973, nosmanicipios de Alfredo Chaves, Rio Novo do Sul e Serra, mostrou que numa ărea em produção da ordem de 13.560 hectares, as lavouras apresentavam uma idade mëdia de cerca de 10 anos e eram plantadas em espaçamento maior que o recomendado.

Os técnicos encontraram dificuldades em promover a renovação das lavouras, com técnicas modernas, uma vez que isso privaria o produtor de sua renda corrente, no período de formação de novos bananais.

o baixo rendimento observado na cultura se deve principalmente à inadequaçäo das áreas àe cultivo, ac baixo nivel tecnológico e à elevada idade média das lavouras.

A assistência técnica oficial vem fazendo es-forços para assistir os produtores de banana. Assim, ern 197071, somente 3,0\% da área cultivada com bananeira eram assistidos pela EMATER-ES. Em 1979-80, ela assistia cerca de 41,28 daquele total. Para essas mesmas áreas e mesmo periodo o uso de defensivos passou de $1,3 \mathrm{~kg} / \mathrm{ha}$ para 2,5 kg/ha; o plantio de mudas selecionadas passou de 88,5 mudas/ha, para 204,5 mudas/ha; e o uso de fertilizantes de $226 \mathrm{~kg} / \mathrm{ha}$ para $199 \mathrm{~kg} /$ ha. Mostrou-se assim que, apesar da expansão da área assistida, pouco se conseguiu em melhorias tecnológicas para essa cultura.

As lavouras de cacau estão concentradas no município de Linhares, onde se obtém $92,6 \%$ da produção do Estado. Este município se caracteriza como zona tropical úmida, com inverno seco, propício à lavoura cacaueira.

o crescimento do rendimento, verificado na lavoura de cacau, se deve principalmente ao trabalho que a CEPLAC - Comissão Executiva do Plano da Lavoura Cacaueira,vem 
desenvolvendo no Estado, conjugando serviços de pesquisa e ex tensão.

A pesquisa conduzida para a lavoura cacaueira, pelo Centro de Pesquisa do Cacau - CEPEC, vem desenvol vendo variedades híbridas, que elevam produtividade, preco cidade e resistência a doenças.

Estes novos conhecimentos são levados aos cacauicultores através do Departamento de Extensão - DEPEx, notando-se resultados bastante favoráveis. Em 1971/72, em 18,6\% da área total cultivada, fazia-se combate de pragas entomológicas. Em 1979/81, esta parcela chegou a 83\% daquela área total. Quanto ao combate à doenças, no início da década de 1970, ela não era adotada. Em 1979/81, em cerca de 23\% da área total cultivada era prática adotada. 


\section{CONCLUSÓES}

Os resultados desta pesquisa evidenciam que os efeitos de área, rendimento e composição são importantes, em termos de explicação de variações na taxa geométrica de crescimento da produção agrícola estadual, nos períoảos 1970 $-75,1975-80$ e $1970-80$.

Dentre as variáveis explicativas da taxa de crescimento do proauto agrícola, o efeito de rendinento é o mais importante, sugerindo que a agricultura capixaba, na quela década, teria sentido os efeitos das politicas de in centivo à modernização, como a expansão dos serviços de ex tensão rural e de crédito subsidiac̄o.

O segundo efeito de maior importância rela -tiva é o de composição. Esse efeito atribuiu maior imp̧ortān-.. cia aos municípios em que ocorreu maior expansão do café, evidenciando que a introdução dessa lavoura, com novos padrões tecnológicos, contribuiude forma positiva para o aumento da produção agrícola dos municípios.

A evidência emoirica ora obtida que atribuiu maior relevo a esses dois efeitos, em termos de exploração de crescimento do produto de lavoura, no Espirito Santo, se contrasta com os resultados de pesquisas realizados em outras unidades de Federação, nos quais o efeito-área parecia ser o de maior importância.

O efeito-área é de menor importância na exploração de variações nas taxas geométricas de crescimento 
da agricultura capixaba, na décała de sessenta. No que a esta constatação, pode-se sugerir, com relativa segurança, que isso se deve a dois motivos principais. O primeiro diz respeito às áreas agrícolas disponíveis, no Estado, já relativamente escassas, principalmente nas Regiões sul e serrana. Os resultados ora obtidos permitem concluir que, nas cultu ras de mercado interno, como arroz, feijão e milho, o efeito de rendimento sobre a taxa geométrica de crescimento das culturas é relacivamente menor quando comparado ao de culturas de mercado externo, como cacau e café.

Este resultado é coerente com o de outras pesquisas, realizadas no País, nas quais as culturas voltadas para mercado externo receberam, relativamente, maiores incentivos do governo, tais como os benefícios da pesquisa cien tífica e da assistência técnica.

Dentre as culturas de mercado interno, a exm cessão a esta regra é o tomate, para a qual o efeito de rendimento é relativamente alto. Essa atividade foi beneficiada por assistência técnica mais efetiva, pela introdução de novos padrões tecnológicos, e pelo incentivo de mercado,principalmente aquele referente à Grande Vitóra.

O efeito de área é negativo ou praticamen te nulo, em todas culturas e todos os periodos. No período de 1975-1980 o efeito-área só assume importância relativa para as culturas da cana e do café.

Conclui-se, portanto, que a agricultura do Espírito Santo, na década de 1970 apresentou resultados favoráveis, com relação à produtividade da terra. Constatação essa importante para orientação da politica aquícola estadual, que mostra a relevāncia que deve ser dada aos incentivos à tecnologia e investimento.

O segundo motivo, se relaciona ao fato de que as áreas disponíveis na Região Norte do Estado foram ocupadas principalmente por pastagens e reflorestamento. A 
primeira contou com recursos do CONDEPE, com crédito farto e com taxas de juros reais negativas. A expansão das áreas com eucalipto, para atender a indústria de celulose, foi estimulada, com incentivos fiscais e recursos do BNDES. Por tanto, entre as possibilidades de aumento da produção do subsetor de culturas, uma foi o aumento da produtividade da terra, através do uso melhores tecnologias e outra a mudança na estrutura de cultivo, substituindo culturas de menor para culturas de maior produtividade.

Os resultados da análise individual das lavouras são análogos aos dos municípios, onde o efeito-rendimento se mostra como a principal fonte de crescimento das culturas, em todos os periodos, com excessão de mandioca e banana, nas quais esse efeito é negativo. 


\section{REFERÊNCIAS BIBLIOGRĀFICAS}

ARAUJO, P. F. L. Análise da política de crëdito à agricul tura brasileira. Piracicaba, 1980. 225 p. (Livre Docência - Escola Superior de Agricultura "Luiz de Queiroz" USP ) .

BRASIL. Empresa de Assistência Técnica e Extensão Rural do Espirito Santo. Relatório de atividades. Vitória, se cretaria da Agricultura, s.d., s.p.

- Fundação Getúlio Vargas. Preços recebidos pelos agricultores. Rio de Janeiro, Centro de Estudos Agrícolas, s.d., s.p.

Fundação Instituto Brasileiro de Geografia e Estatis-tica. Producão agricola municipal: Minas Gerais e Espiri.-. to santo. Rio de Janeiro, SEPLAN, 1976. 362 p.

- Produsão agrícola municipal: Minas Gerais e Espirito Santo. Rio de Janeiro, SEPLAN, 1972. 326 p.

- - Produsão agrícola municipal: Minas Gerais e Espirito Santo. Rio de Janeiro, SEPLAN, 1973. $323 \mathrm{p}$.

- Produsão agricola municipal: Minas Gerais e Espirito Santo. Rio de Janeiro, SEPLAN, 1976. 360 p. 
- Producão agricola municipal: Minas Gerais e Espirito Santo. Rio de Janeiro, SEPLAN, 1977. 325 p.

- Produsão agricola municipal: Minas Gerais e Espirito Santo. Rio de Janeiro, SEPLAN, 1978. 324 p.

- Producão agricola municipal: Minas Gerais e Espirito Santo. Rio de Janeiro, SEPLAN, 1981. 360 p.

BRASIL. Fundação Instituto Brasileiro de Geografia e Esta tistica. Producão agricola municipal: Minas Gerais e Espirito Santo. Rio de Janeiro, SEPLAN, 1982. 325 p.

- _ Produsão agrícola municipal: Minas Gerais e Espirito Santo. Rio de Janeiro, SEPLAN, 1983. 323 p.

Ministério da Agricultura. Crédito rural: perfis de distribuifão e dados estatisticos, 1969/1976. Brasilia, $\mathrm{DF}, \mathrm{v} .2,1977.210 \mathrm{p}$.

CUNHA, Aércio dos Santos \& DAGUER, Regina J. Crescimento agrícola: área vs produtividade, XX Congresso Brasizeiro de Economia e Sociologia Rural, Curitiba, SOBER, Anais..., 1982 .

CURTIS, wayne C. Shift-share analysis as a techniques in rural development research. American Journal of Agricultural Economics, Gainesville, 54(2): 267-270, 1972.

GREENIR, T. \& ALLAWAY, A. W. Identification of export opportunities: a shift-share approach, Journal of Marketing, Chicago, $49(1): 83-88,1985$. 
HAYAMI, Y. \& RUTTAN, V. W. Diferenças de produtividade agrícola entre nações. In: CIDADE DE ARAUJO, P. F. \& SCHUH, G. E. Desenvolvimento da Agricultura (Educasão, Pesquisa e Assistência Técnical, São Paulo, Livraria Editora Pioneira, 1975. p. 77-100.

HOFFMANN, Rodolfo \& KAGEYAMA, Angela A. iodernização da agricultura e distribuição da renda no Brasil, Conferén cia Latinoamericana de Economia Agricola, Piracicaba, 1984.

IGREJA, A. C. M. Anälise quantitativa do desempenho da agricultura paulista, 1966-7?. São Paulo, Instituto de Economia Agrícola, 1982, RP 7/82. 35 p.

KALBACHER, J. Z Shift-share analysis: a modified approach. Agricultural economics research, washington, D. C., 31(1): $12-25,1979$.

LEDEBUR, L. C. \& MOOMAN, R. L. A shift-share analysis of regional labor productivity in manufacturing. Growth and change, Lexington, 14(1): 2-9, 1983 .

NELO, F. H. A composição da produção no processo de expan são da fronteira agrícola brasileira, Conferéncia Latinoamericana de Economia agricola, Piracicaba, 1984.

I.IENDONÇA DE BARROS, J. R.; PASTORE, A. C. \& RIZZIERI, J.B. Participação do índice de produtividade da terra entre os componentes alocativo e tecnológico. Pesquisa e Planejamento Econömico, 6(3): 755-766, 1976.

- A evolução recente da agricultura brasileira. In: CIDADE DE ARAÚJO, P. F. \& SCHUH, G. E. Desenvolvimento da Agricultura (Estudos de Casos), São Paulo, Livraria Editora Pioneira, 1983. p. 257-278. 
MOTtA, N. C. As conseqüencias da implantacão do projeto Aracruz Celulose sobre a estrutura economica da região de Linhares. Rio Claro, 1982. $82 \mathrm{p}$. (Mestrado Instituto de Geociências e Ciências Exatas da UNESP).

PATRICK, G. F. Fontes de crescimento da agricultura brasileira: o setor de culturas. In: CONTADOR, C. R. T'ecnologia e Desenvolvimento Agrícola, Rio de Janeiro, IPEA/INPES, 1975. p. 89-110 (Série Monográfica, 17).

SALGADO, M. M. T. Transformasões na economia agrícola dos municipios do Espirito Santo: 1960-1975. Viçosa, 1982. 89 p. (Mestrado - Universidade Federal de Viçosa).

SMITH, G. W. A politica agricola brasileira: 1950-1967. In: CIDADE DE ARAŨJO, P. F. e SCHUH, G. E. Desenvolvimento da Agricultura (Estudos de Casos), São Paulo, Livraria Editora Pioneira, 1983. p. 213-256.

THOMPSON, R. L. The metaproduction funcion for Brasizian agriculture: an analysis of productivity and other aspects of agricultural growth. Lafayette, Purdue University, 1974. 177 p. (Tese de Ph.D.) .

VERA FIIHO, F. \& TOIJIIJI, H. Progresso tecnológico e desenvolvimento agrícola. In: VEIGA, A. Ensaios sobre politica agricola brasileira. São Paulo, Secretaria da Agricultura, 1979. p. 87-136. 